\title{
THE EFFECTS OF MONOLINGUAL AND BILINGUAL DICTIONARIES ON EFL LEARNING FOR STUDENTS AT DBE AT METU
}

\author{
Büşra Nur DURMAZ ${ }^{1}$ and Gülçin DÜDÜKÇÜ² \\ ${ }^{1}$ Middle East Technical University, Foreign Language Education. \\ ${ }^{2}$ Middle East Technical University, Foreign Language Education.
}

\section{Abstract}

Dictionaries are the most importantpart of second language acquistion since they are used at every level of language learning. People use them while writing, reading, watching movies or listening to music in the language they are learning. They may choose different dictionaries for different activities since there are different types of dictionaries including monolingual and bilingual dictionaries.

We focused on these two types of dictionaries in this research and we examined reasons behind the usage of monolingual and bilingual dictionaries among ESL students at Metu DBE ( Department of Basic English)

Key Words: Dictionary; Monolingaul Dictionary; Bilingual Dictionary.

\section{INTRODUCTION}

Learning a second language is a very demanding deed; therefore, there are thousands of books and different strategies to make it easier for people. One of the most useful ways for language learning is dictionary usage. According to Oxford Advanced Learner's Dictionary (2006), the word "dictionary" means; 'a book that gives a list of the words of a language in alphabetical order and explains what they mean, or gives a word for them in a foreign language'. That is, dictionaries are tools which can be made use of in more than one aspect for second language acquisition. Therefore, it is really important to choose the kind of dictionary which meets one's needs in the best way.

Wingate (2004) confirms that dictionaries are loyal assistants for a language learner. Tarp (as cited in Gouws, 2004) underlines that functions of a dictionary must be set down according to the needs of the intended user of the dictionary. As future English language teachers and still learners of English, we need to consider how to make the best use of dictionaries for both ourselves and our students in the future. We also need to take into consideration that students at different levels of learning English may differ in the type of dictionaries they need (Shanshan, 2008). As we know, there are 3 types of dictionaries that are used, which are; monolingual, bilingual and bilinguilised (Shanshan, 2008), but in this research we are going to look into the usage of the first two.

Bilingual dictionaries involve L1 equivalents of L2 words. So, it is easy to look a word up in a bilingual dictionary. Monolingual dictionaries, on the other hand, provide information only in the target language (Fan, 2000). Compilations of monolingual dictionaries are done by native speakers in an authentic environment; therefore, language changes are first received by monolingual dictionaries (Shanshan, 2008). Bilingual dictionaries, on the other hand, are translations of monolingual dictionaries, thus their update rate is not as fast as that of monolingual dictionaries (Shanshan, 2008). Inherently, monolingual dictionaries seem to be more challenging for non-proficient English learners (Holi Ali, 2012) since they contain more detailed linguistic information compared to bilingual ones.

These notions led us to do a comparative research between beginner and advanced (we wanted to see the ideas of students of the highest and the lowest levels) level learners of English in order to find out the thoughts of second language learners in terms of dictionary usage. Through such a study, we can contribute to students' effort in EFL learning, especially in English-medium universities like METU.

Although there have been several research studies about the usage of monolingual and bilingual dictionaries, they mostly put forward an assumption before they have done their research. However, in this study, we have done our study just to determine the reasons behind students' choices of certain type(s) of dictionary(ies) and impact of their choices on English language learning without any anticipation and assumption. To the best of our knowledge, so far the researchers have looked into the effects of a dictionary usage on a specific skill, for example on 'vocabulary recall' or 'reading comprehension' (Hayati \& Fattahzadeh, 2006). Nevertheless, our research is about the effects of dictionary usage on English as a Foreign Language in general.

In this study we aimed to determine the frequency of usage of monolingual and bilingual dictionaries by beginner and advanced level students at Department of Basic English at METU and reasons behind their usage with the effects of their choices on EFL. In this study the following questions will be asked:

1. Which type of dictionary/ dictionaries do students in beginner and upper-intermediate level at DBE at METU mostly prefer to use?

2. What are the reasons for preferring a certain type of dictionary?

3. What are the perceived advantages of the dictionary/ dictionaries the participants choose to use? 


\section{ISSN $2348-3004$ \\ Volume $6 \mathrm{Number} 2$ \\ Journal of Advances in Linguistics}

\section{METHODOLOGY}

Since our research questions are about the reasons and personal advantages of dictionary usage, we conducted only interviews with students in order to learn their personal opinions and compare their answers with each other on the subject.

\subsection{Participants}

The participants of the investigation will be chosen from the Department of Basic English at Middle East Technical University. The intended number of our participants is eight. Four of them will be beginner level students and the other four of them will be upper-intermediate level students at DBE at METU. We will choose beginner and upper-intermediate students to do interviews since we wanted to compare the lowest and highest level in order to see the difference of their choices and possible outcomes of their decisions. So, we will select our participants by using stratified random sampling method. We preferred this method because we will disregard the gender, age and educational background of the students while selecting them. Furthermore, we used convenience sampling method. We chose our setting as the Department of Basic English at METU because we are studying in METU. Thus, it is easy to reach the participants and the information about the institution.

\subsection{The Setting}

The Department of Basic English at METU prepares students for their undergraduate studies in terms of usage of basic language skills. The department offers a two-semester intensive program by attaching great importance to reading, writing, speaking and listening. There are five groups of students in the department. The groups are determined according to success of the students in the placement exam. The levels of groups are beginner, elementary, intermediate, upperintermediate and repeat in the first semester. In the second semester, the levels of groups become elementary, intermediate, upper-intermediate, advanced and repeat. During the semesters, the students go through quizzes and exams about all the language skills. Also, they have three midterm exams including listening, reading and writing skills. To complete the preparatory school, the students need to be successful in not only the exams above but also the English Proficiency Exam at the end of the year.

\subsection{Instrument}

We will collect the data through an interview. The interview questions were adapted from a related research (Shanshan, 2008). We used semi-structured interview method. The following questions will be asked to interviewees:

1. What kind of a dictionary do you use while studying English?

2. How often do you use a dictionary?

3. Do you use a specific kind of dictionary for a specific purpose?

4. Are there any advantages of the dictionary/dictionaries you use? If so, what are they?

\subsection{Data Collection Procedure}

All the interviews will be conducted in Turkish because the interviewees may be more comfortable expressing themselves in their native language.

We think that for interview, we do not need to get permission from the Department of Basic English. Thus, we will only ask permission of interviewees. Before starting with the interviews, the interviewees are supposed to sign a paper showing that they agree to participate in the interviews voluntarily and accept that their voice will be recorded during the interviews. Also, they are supposed to give their consent that we might quote their utterances by keeping their identities secret. However, they will not be informed in detail about the content of the research so that they will not shape their answers according to our expectations.

The interviews are going to be conducted at the place where each interviewee desires to do.

\subsection{Data Analysis}

Each interview will be recorded by the consent of each interviewee. Then, all of the records will be transcribed word for word by us. We will analyze the transcriptions through content analysis.

Renner and Taylor-Powell (2003) suggested certain steps in their paper to analyze qualitative data and we will follow those steps while examining our interview data. First, we will write down our impressions about the data. Then, we will focus on our interview questions to categorize the information. We will use preset categories because we will have asked the same questions to interviewees and will have got similar answers. After that, we will seek for connections within and between categories. Also, we will compare what we are expecting before conducting interviews and what we will learn new after analyzing the data. 


\section{ISSN $2348-3004$ \\ Volume $6 \mathrm{Number} 2$ \\ Journal of Advances in Linguistics}

\section{RESULTS}

\subsection{Interview Question 1}

The first interview question was which kind of dictionary the interviewees use while studying English.

Table 1 - The type of dictionaries the participants use

\begin{tabular}{|l|c|c|c|}
\hline Level of students & Usage & Usage & Usage \\
\hline & Only Monolingual & Only Bilingual & Both Monolingual and Bilingual \\
\hline Beginner & 0 & 3 & 1 \\
\hline Upper-Intermediate & 0 & 1 & 3 \\
\hline
\end{tabular}

The answers showed us that each participant uses a bilingual dictionary no matter whether they are beginner or upperintermediate level students. Four participants use only bilingual dictionaries; three of them are beginners and one is upperintermediate. However, the other four use monolingual dictionaries together with bilingual ones. They consist of three upper-intermediate and one beginner level students. Moreover, the majority of the bilingual dictionary users look up words in online dictionaries which are also bilingual.

\subsection{Interview Question 2}

The second question of the interview investigated the frequency of the participants' usage of a dictionary. The students answered this question without emphasizing when they use which kind of dictionary. Two beginner students and two upper-intermediate ones use dictionary quite often, like almost every day. Two students at beginner level reported that they use dictionaries 3-4 days in a week. The rest two of the upper-intermediate students stated that they look up a dictionary 2-3 days in a week.

\subsection{Interview Question 3}

The third question in the interview aimed to learn if the participants use a specific dictionary for a specific purpose. Table 3 shows the results to this question.

Table 3 - Do you use a specific kind of dictionary for a specific purpose?

\begin{tabular}{|c|c|c|c|c|c|}
\hline & Studying & Reading Book/Texts & $\begin{array}{l}\text { Watching } \\
\text { Movies }\end{array}$ & $\begin{array}{l}\text { Surfing on the } \\
\text { Internet }\end{array}$ & Writing \\
\hline $\begin{array}{l}\text { Participant } \\
\text { A }\end{array}$ & Bilingual & & & Bilingual & \\
\hline $\begin{array}{l}\text { Participant } \\
\text { B }\end{array}$ & Bilingual & & & & \\
\hline $\begin{array}{l}\text { Participant } \\
\text { C }\end{array}$ & $\begin{array}{l}\text { Monolingual } \\
\text { Bilingual }\end{array}$ & Bilin & & & \\
\hline $\begin{array}{l}\text { Participant } \\
\text { D }\end{array}$ & Bilingual & & & & \\
\hline Participant E & - & Bilingual & & Online Bilingual D. & \\
\hline Participant F & $\begin{array}{l}\text { Bilingual } \\
\text { Monolingual }\end{array}$ & $\begin{array}{ll}\text { Phrasal } & \text { Verb } \\
\text { Dictionary } & \end{array}$ & $\begin{array}{l}\text { Online Bilingual } \\
D .\end{array}$ & & \\
\hline $\begin{array}{l}\text { Participant } \\
\text { G }\end{array}$ & & Monolingual & & Online Bilingual D. & Bilingual \\
\hline $\begin{array}{l}\text { Participant } \\
\mathrm{H}\end{array}$ & Monolingual & & Monolingual & Monolingual + Bilingual & \\
\hline
\end{tabular}

This data shows us that three of the participants use only bilingual dictionary when they are studying English, all of which are beginner level students. One beginner and one upper-intermediate participants use bilingual dictionary while reading an English book or text, whereas one upper student uses monolingual dictionary for the same purpose. Another upper participant uses phrasal verb dictionary as an exception. One of the participant of upper-intermediate students uses online bilingual dictionary while watching movies in English, and one of them uses monolingual dictionary for the same purpose. Two of the upper-intermediate participants use online bilingual dictionary while surfing the Internet, whereas one upperintermediate student uses both monolingual and bilingual dictionary. One beginner student uses only bilingual for the same purpose. Finally, one of the participants who is an upper-intermediate level student uses bilingual dictionary for writing in English. 


\subsection{Interview Question 4}

With the fourth question in the interview, we intended to learn whether there are any advantages or disadvantages of the dictionaries the learners use and if so, what they are. Table 4 shows the results to this question.

Table 4- Advantages and Disadvantages of Dictionaries

\begin{tabular}{|l|l|l|l|}
\hline & Advantages & Disadvantages & Number of Participants \\
\hline $\begin{array}{l}\text { Monolingual } \\
\text { Dictionary }\end{array}$ & $\begin{array}{l}\text { C and D(beginners) G and H( upper- } \\
\text { intermediate) }\end{array}$ & Participant C only & $\begin{array}{l}4 \text { beginner, } 4 \text { upper- } \\
\text { intermediate }\end{array}$ \\
\hline Bilingual Dictionary & $\begin{array}{l}\text { A and B(beginners), E and G( upper- } \\
\text { intermediate) }\end{array}$ & $\begin{array}{l}\text { A and D(beginners) } \\
\text { E and H (upper } \\
\text { students) }\end{array}$ & $\begin{array}{l}4 \text { beginner, } 4 \\
\text { intermediate upper- }\end{array}$ \\
\hline
\end{tabular}

As we already stated in the first interview question, all of the participants use bilingual dictionary, yet four of them (1 beginner, 3 Upper) use monolingual along with the bilingual dictionary. Four of them (2 beginner, 2 upper- intermediate students) stated that using a bilingual dictionary is advantageous because;

- It gives them the meaning of the words directly ( Participant A and B [beginners] and Participant E [upperintermediate] )

- Finding words in bilingual dictionary is easy and quick. ( Participant G [upper-intermediate] )

Four of them stated the disadvantages of bilingual dictionaries saying that it does not give collocations. They also argue that bilingual dictionaries give more than one meaning of a word without using them in a context as an example, which is confusing.

On the other hand, four of the participants stated that using monolingual dictionary is advantageous for them. Their reasons are that;

1. A Monolingual dictionary enables them to think in English. ( Participant $\mathrm{G}$ and $\mathrm{H}$ [upper-intermediate] )

2. It shows how the words are used in a sentence. ( Participant $\mathrm{G}$ [upper-intermediate] )

3. It is more effective in SLA because it explains words with their synonyms in English. (Participant D [beginner] and Participant $\mathrm{H}$ [upper-intermediate] )

4. It enables her to learn meaning of other words which are used to explain the word she is looking for. ( Participant C [beginner] )

The one and only participant who said that monolingual dictionary was disadvantageous was Participant $\mathrm{C}$, with the reason that there are also unknown words in the explanation of the words which she was trying to learn. However, previously, she refuted this idea herself by turning this reason into an advantageous one as we stated above.

\subsection{Interview Question 5}

We wanted to learn if the instructors of the participants suggested any kind of dictionary to them. Three beginner and three upper students said that their instructors suggested them to use a monolingual dictionary. One beginner and one upper student stated that their instructors did not suggest them any dictionary.

However, students who do not use monolingual dictionary, despite the advice of their instructors, claimed that they felt they were not proficient enough to use a monolingual dictionary. Also, they claimed that bilingual ones were easier to look up anyway.

\section{DISCUSSION}

As we mentioned before, our purpose of the study is to learn the differences between the choices of dictionary of beginner and upper-intermediate students of English. We wanted to compare their reasons and thoughts about their choices of dictionary, because as most of the linguists stated, we think that dictionaries play a crucial role in second language acquisition.

Our results indicate that whether a student is a beginner student or an upper-intermediate student, s/he uses bilingual dictionary. Nevertheless, upper-intermediate students use monolingual dictionary in addition to the bilingual one. Students who use dictionary besides studying English are mostly the upper-intermediate students. The ones who use dictionary besides studying reported that although they use monolingual to study, they use mostly bilingual when they are watching movies or writing to get the meaning of the unknown word quickly. For example, one participant (G) who is an upperintermediate student uses both monolingual and bilingual. She answered the 3rd interview question as;

"I always use Bilingual dictionary while writing, but I try to use monolingual dictionary while reading because it makes me think in English. I use online bilingual dictionaries while wathcing TV show due to its easiness."

And another participant who is from Kazakhstan and an upper student, said ;

997 I P a g e

March 2016 
"While I study or watching movies I use bilingual dictionary. Other than that I usually use monolingual dictionary."

As we can deduce from the answers, participants from both levels think that bilingual dictionary is much easier to use since they get the direct meaning of the words in their native language. Bilingual dictionary seems to be more practical in usage for both levels of students.

Our results are in some respect parallel with the findings of other researchers on the same topic. Shanshan (2008) asserts that most of the time the students look up bilingual dictionaries while studying. Holi Ali (2012) finds out in his study that most of the students use bilingual dictionaries more when compared to ones using monolingual and bilingualized dictionaries. However, some of our results contradict with the findings of other researchers. Laufer and Hadar (1997), based on their research study, claim that the students do not have to be proficient in the target language to use a dictionary; in that case it is monolingual. Nevertheless, our participants who do not use monolingual dictionaries point out that they do not fully understand the explanation of the word given in the target language.

\subsection{Bilingual Dictionaries in the Perspectives of Beginner and Upper Students}

Answers to 3rd question also correspond to the answers to the 4th question of the interview, which was; "Is there any advantage or disadvantage of the dictionary (ies) you use? If so, what are they? "

In their answers, students from both levels indicated that bilingual dictionary is like their easy way out to find the meanings of words, as one of the beginner participants said;

"( For English-Turkish dictionary ) One advantage of it is it give the direct Turkish meaning of a word. It is very easy and quick to look a word up."( Participant B)

Also, Hayati and Pour-Mohammadi (2005) emphasize that bilingual dictionaries are effective on the students' reading skills. It is because finding the meaning of the target word is easy in bilingual dictionary, which encourages the students to make use of the dictionary. It is one of the advantages of using bilingual dictionaries.

However, as for the disadvantages of bilingual dictionary, students from both levels (\%50 of the participants) think that bilingual dictionaries have some drawbacks. They mostly believe that bilingual dictionaries do not give the words in context, so students can choose one of the meanings they need at that moment. As one beginner level participant said;

"In terms of desadvantages, there are more than one meaning to a word. It can be really confusing. "(Participant $A)$

One upper student also said almost the same thing;

"The only desadvantages is that it does not give a word in a sentence to show how it's used." (Participant E)

Although beginner participants say for this downside of the bilingual dictionaries that these are very confusing for them, they do not attempt to use monolingual dictionaries in that sense, whereas upper participants also use monolingual dictionary along with the bilingual one.

\subsection{Monolingual Dictionaries in the Perspectives of Beginner and Upper Students}

The reasons for using monolingual dictionary of upper students are mostly that these kinds of dictionaries keep them in an English setting. In other words, these dictionaries enable them to think in the target language, in our case English, and therefore these are more effective in their second language acquisition. That is because monolingual dictionaries are created by the natives of that language (Shanshan, 2008).

As stated in a study (Shanshan, 2008), some of the students are aware of the benefits of monolingual dictionaries though they do not use them. One of the beginner participants, although she does not use monolingual dictionary since she thinks her English is not proficient enough to use it, said that she thought monolingual ones could be more beneficial for her to remember words afterwards. Her exact words were;

"...for example there is a vocabulary source of METU, there the explanations for words are given in English. They use synonyms to explain unknown words. That way I can keep the words in my mind. It gives an example of the word in a sentence. It makes me understand the word well. I never used a monolingual dictionary but I assume that it should be something like that."

Additionally, another beginner participant $(\mathrm{C})$, the only beginner who uses bilingual along with monolingual, claimed that it helps her to learn different words when she encounters an unknown word in an explanation of a word. However, she first mentioned that as a disadvantage. Other than the participant $\mathrm{C}$, no one, neither beginner nor upper-intermediate participants, mentioned a disadvantage of a monolingual dictionary.

Most of the participants (\%75) said that their instructors suggested monolingual dictionary for them. Three of them were beginner students and the other ones were upper-intermediate students. The other two stated that their instructors did not suggest any kind of dictionary. This means that, no instructor recommended bilingual dictionary, whether s/he was a beginner or upper teacher. Shanshan (2008) gives a reason behind the choices of the instructors. She claims that the instructors find monolingual dictionaries more clear-cut in meaning and helpful to make students think in English. Therefore, we can deduce that contrary to the belief of beginner students, their instructors do not think their students as inadequate for monolingual dictionaries; rather they seem to be perceiving monolingual dictionaries as a step to improve the English level of beginner students. However, as we mentioned above, our participants see themselves as inadequate 


\section{ISSN $2348-3004$ \\ Volume $6 \mathrm{Number} 2$ \\ Journal of Advances in Linguistics}

for using monolingual dictionaries. So, we can see that our participants and their instructors have opposite ideas about the usage of dictionaries.

\section{CONCLUSION}

We tried to investigate the opinions of the students about the habits of dictionary usage. We also made comparison between the students at different levels. So, we found that, no matter what the proficiency level of the students in English is, students cannot give up on using bilingual dictionaries. In other words, bilingual dictionaries are the ones which are mostly used by the students (Shanshan, 2008) in preparation school at METU thanks to its practicality. Monolingual dictionaries, on the other hand, are used mostly by upper-intermediate students as a supplementary source to bilingual ones. They are used complementary to one another in a sense, as also suggested by Shanshan.

Even if the half of the participants does not use it, they accepted that the monolingual dictionary is advantageous. However, they still cannot quit using bilingual dictionary and start using only monolingual dictionary for the sake of their English.

This is partly because they do not want to bother themselves with monolingual dictionary since it is more complex and challenging compared to a bilingual dictionary in which they directly learn the equivalent of the words they do not know in their native language. Also it is mostly because beginner students think that their proficiency level is not enough to use a monolingual dictionary, which is exactly why their instructor wants them to use it.

As for the implications of our study, it can be said that it confirms the results of other research studies on the same topic. However, our study is slightly different from them because our setting is the Department of Basic English in an Englishmedium university, METU. It means that our participants are exposed to only English during their classes. They will also get a college education only in English when they move on to their departments. So, they need to be proficient enough in English to pursue their undergraduate studies. When we take into consideration that dictionaries have a crucial role in second language acquisition, it is important to find out the opinions of the students in this setting. Thanks to our study, we have a chance to hand the microphone to just few of the students. Our study reveals that the students in this setting use dictionary a lot and believe that their dictionaries have effects on their learning of language.

While we were conducting our interviews, we could have got more information from the participants. However, they seemed to be a little reluctant to say more things on the topic. Every time we conducted an interview, we expected to expand our results. Nonetheless, their answers were similar.

We have some suggestions for further investigations on the topic. To get more general information, the study might be conducted with the students in all levels at DBE at METU. Also, it is possible to choose another preparatory school in another university besides METU so that the two settings can be compared in terms of the habits of dictionary usage.

\section{REFERENCES}

[1] Ali, H. (2012). Monolingual Dictionary Use in an EFL Context, English Language Teaching, Vol.5, No.7, 2-7. doi: 10.5539/elt.v5n7p2

[2] Fan, M.Y. (2000). The Dictionary Look-Up Behavior of Hong Kong Students: A Large Scale Survey, Education Journal,Vol.28, No.1, 123-138

[3] Gouws, R.H. (2004). Monolingual and Bilingual Learners' Dictionaries, Lexikos, Vol.14, 264-274

[4] Hayati, M.,\& Fattahzadeh, A. (2006). The Effects of Monolingual And Bilingual Dictionaries on Vocabulary Recall And Retention of EFL Learners, The Reading Matrix, Vol.6, No.2

[5] Oxford Advanced Learner's Dictionary (7 $7^{\text {th }}$ ed.).(2006). Oxford, Oxford University Press.

http://www.oxforddictionaries.com/

[6] Shanshan, C. (2008). Monolingual, Bilingual Dictionaries and Language Study, Cross Cultural Communication, Vol.4, No.1, 65-73

[7] Wingate, U. (2004). Dictionary Use- The Need to Teach Strategies, Language Learning Journal, No.29, 5-11 